1940). “. . . the oceanography book . . . has hung as a sword of Damocles over my head for several years . . ." (December 1941). "It is a volume of nearly 1,100 pages, which I hope will remain a standard work for some years to come. I cannot send you a copy now . . ." (March 1943). "I would greatly appreciate it if you would send me Ekman's review of it. Up til now its been reviewed primarily by biologists or geographers, who have not been especially competent on matters of physical oceanography. There has therefore not been especially much discussion of my effort to treat the masses of water and currents in the ocean from a unified perspective." (November 1945). What made Harald undertake this bruising task? I believe the answer must be that he felt compelled to demonstrate the underlying unity of oceanography, its physics, chemistry, biology, and geology, a conviction he developed during seven years of arctic exploration aboard the Maud.

If I were to review my copy of "The Bible" after 50 years of use, I would have to say that it has not stood up at all well. The back cover is barely attached, and some of the fold out charts remain connected to the rest of the book only by repeated applications of sticky tape. But then, what can you expect for 135.9 pages per dollar?

\section{Acknowledgements}

The material quoted is largely from the Sverdrup papers and The Oceans manuscript at the Scripps Archives. I am deeply indebted to Deborah Day, Scripps Archivist.

I am also indebted to Robert Marc Friedman for the following quotations from letters to the
Swedish glaciologist Hans W. Ahlmann (Ahlmann Collection, Center for History of Science, Royal Swedish Academy of Sciences, Stockholm). The 1940 quote in the next-to-last paragraph is a translation by R.M.F.

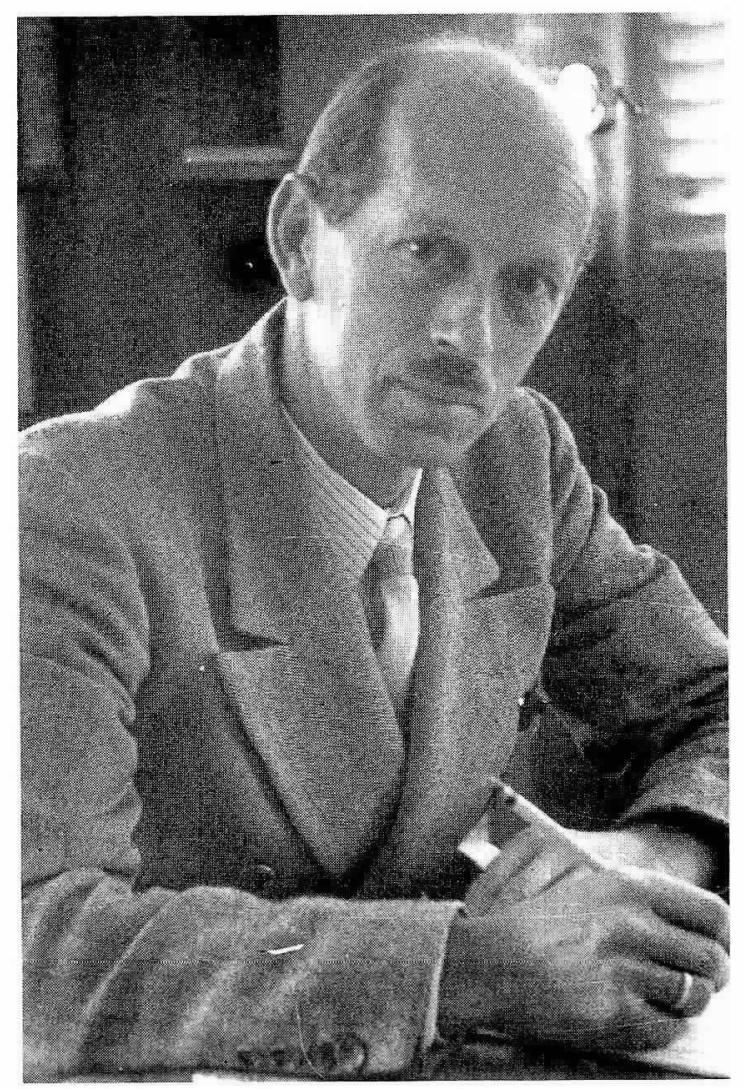

Harald U. Sverdrup
... chapter XV ...

was Sverdrup's

greatest contribution to oceanography.

\title{
Physical OCEANOGRaPhy IN THE OCEANS
}

\author{
By Bruce A. Warren
}

C Columbus ISELIN used to say that Chapter XV of The Oceans, "The Water Masses and Currents of the Oceans," was Sverdrup's greatest contribution to oceanography. It was a masterful, monumental synthesis of information, and it formed a comprehensive account of the physical features

B.A. Warren, Woods Hole Oceanographic Institution, Woods Hole, MA 02543, USA. of the whole world ocean. The only previous work of comparable scope was Krümmel's Handbuch der Ozeanographie, but that was much more a compilation of observations than a synthesis. Sverdrup's style was forthright and decisive, exemplifying the attitude expressed by the book's authors in their preface: "we have . . preferred definite statements to mere enumeration of uncorrelated observations and conflicting interpre- 


\section{Sverdrup's judicious}

water-mass scheme

... still meets this

need better than

anything else yet

devised

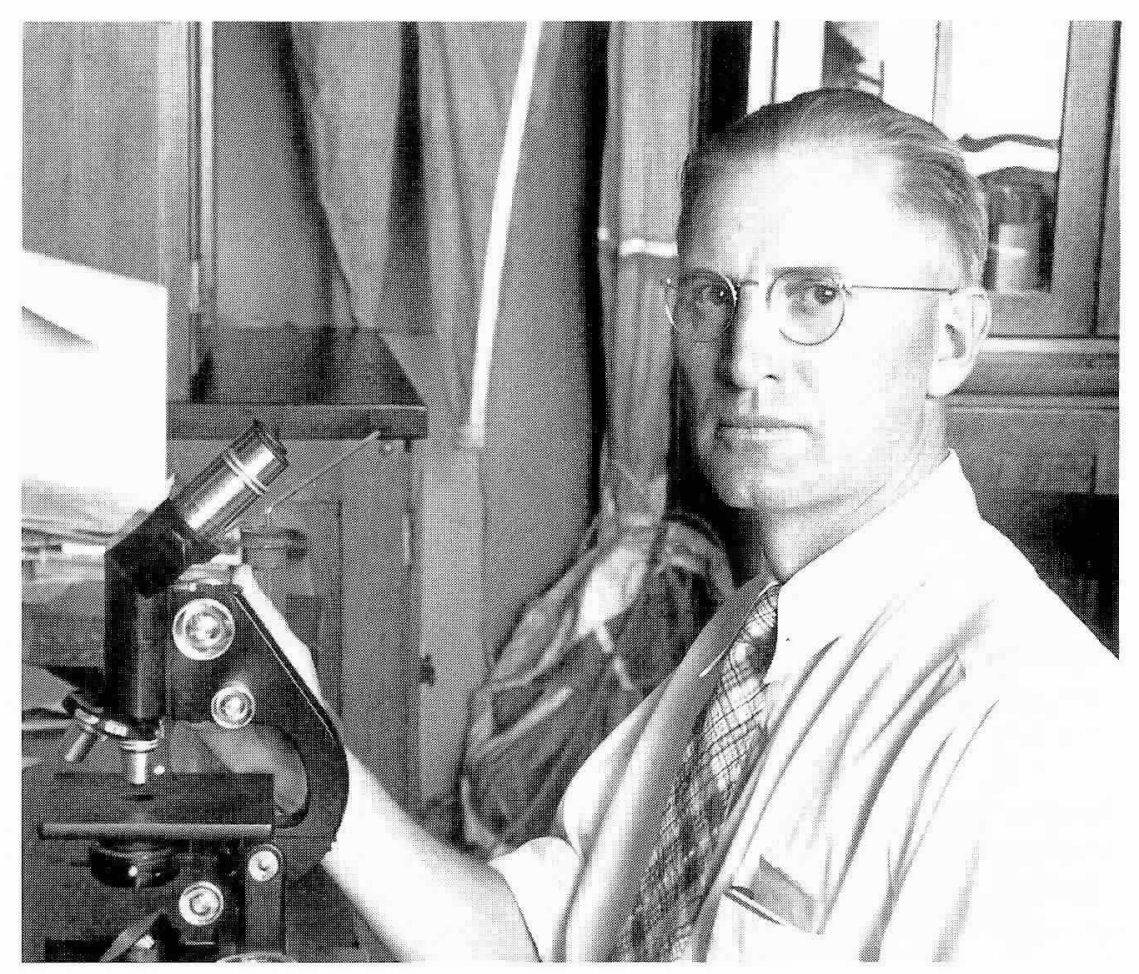

Martin W. Johnson completely discordant with the circulation fields composed of interior flows and western-boundary currents that were later envisaged by Stommel and Arons, and vindicated world-wide by observation.

Sverdrup got a few other things wrong, and of course a lot has been found out since he wrote. He denied any deep overflow across the Greenland-Scotland ridge. Instead, he followed Nansen's misdirection to chimerical convection in the Irminger Sea for the formation of North Atlantic Deep Water. He portrayed an "eastern gyral" in the North Pacific, which does not seem to have stood up to later observations. He must take some blame for prolonging the myth of the Antilles Current, because, while he cited Wüst's transport figure for an "Antilles Current," he omitted to mention Wüst's equal and opposite "countercurrents" on either side of it. He did not speak of the Somali Current or the East Australian Current, but I think his brief remarks about the Agulhas Current and the Indonesian throughflow are not much inferior to summaries of comparable length that one could write today. He did not know of the equatorial undercurrents, nor of poleward undercurrents along eastern boundaries as a global phenomenon, nor did he foresee the vast science of ENSOology that followed from the El Niño phenomenon. Indeed, the very word "thermocline," without which contemporary physical oceanographers could barely converse, appears only 10 times in this 157-page chapter-oddly, only in the descriptions of water masses in the Indian and Equatorial Pacific Oceans.

Is there any benefit, then, in reading Chapter $\mathrm{XV}$ today? I certainly think so: not so much for exact numerical values or other details, but for the overview. The water-property fields in the world ocean are so multifarious that we cannot do without an organizing framework within which to comprehend them, and to discuss our observations of them. Sverdrup's judicious water-mass scheme, with its implied linkages to sources of water types and its possibilities for refinement, still works, still meets this need better than anything else yet devised. Even now his orderly, coherent exposition of the circulatory gyres provides easy access to the broad geography of the current systems, although results from the current-measuring techniques developed and applied during the past four decades have exposed abundant mesoscale structure and supplanted a fair amount of his quantitative detail.

On the other hand, the dynamical material in The Oceans (Chapters XII, XIII, and XIV) is of mainly antiquarian interest now. Sverdrup revised Chapter XII, "Waves and Tides," in 1946, to register the advances in wave prediction that he and Munk had achieved during World War II. Despite this revision, much has been accomplished since then regarding tidal prediction, internal-wave propagation, wind-generation of surface waves, 
that no one would find the chapter rewarding today. Similarly, the exposition of the physics of ocean currents (Chapters XIII and XIV) amounts to little more than geostrophy and the Ekman spiral. Productive circulation theory did not take off until Sverdrup and R.O. Reid developed the idea of basin-scale motion forced by the wind-stress curl, Stommel discovered how the beta-effect makes the gyres asymmetric, and Carrier introduced boundary-layer analysis to simplify the mathematics. But all that happened in the late 1940's, after The Oceans was published.

Before computers, geostrophic velocities and volume transports had to be calculated by hand from the serial observations of temperature, sa- linity, and depth. Therefore an important part of the "dynamics" in The Oceans dealt with the procedure for these "dynamic computations". Perhaps only oceanographers over 50 years old are laden with memories of the interminable, soulsearing tedium of this work: the multiple steps with tables and graphs to reach values of specificvolume anomaly, the double vertical integrations of each of those series by graph, interval-averaging, and summation, and finally (still manually, still enlivened only by the rhythmic clunking of one's desk calculator) the horizontal differencing, level by level, to obtain the velocity and transport distributions. It is a blessing that this part of The Oceans is utterly obsolete.

\title{
The OCEans-Its Relevance Today in Biological OCEanography
}

\author{
By Sharon L. Smith
}

$\mathrm{M}$ ANY EXAMPLES of the important observations made over the past century are included in The Oceans. The description of nanoplankton on the filtration apparatus of Oikopleura has long been one of the most insightful observations in biological oceanography. Its combination of morphology, function, taxonomy and processes, all generated by simple, careful observation and deduction, is still a model of biological synthesis. The degree to which our understanding has not advanced in the intervening years is a surprising realization. The Oceans is full of descriptions of various faunal groups, speculations about their evolutionary history and ecological roles in the sea, and basic definitions that structure our thinking and discussion. The full history of the terms we use is not explained, and some terms are no longer commonly used, but it is clear that The Oceans has played a key role in providing widespread uniformity in some basic terminology of biological oceanography over the past fifty years. Many of the tables in the book provide information of continuing relevance; the conversion of silk number to aperture size for plankton netting is the most used page in my copy of the book.

S.L. Smith, Oceanographic and Atmospheric Sciences Division, Brookhaven National Laboratory, Upton, NY 11973 , USA.
Although much of the biological discussion in The Oceans is highly speculative, its statements of concepts, many yet to be tested, are still often quoted. For example, the general problem of how organisms in the sea avoid being lost to depth is discussed at great length, including the statement “. . . the means of adaptation are mostly along the lines of increased length of appendages, of spines or bristles, or of dorsoventral flattening of the body. . . ."Unfortunately, few quantitative investigations of this hypothesis exist, a situation which has only added confusion to recent attempts to study vertical fluxes of material in the sea. The speculative nature of the text, however, is also a strength because it presents the reader with opportunities to consider ways in which form, function, and populations in the sea came to be shaped as we know them. The evolutionary slant must reflect the focus of biological thought at the time the text was written. but it serves today as a refreshingly different point of view.

When one considers which portions of the biological text seem most "au courant" and which seem most outdated, one gains a sense of where our understanding has advanced over the past fifty years. One realm in which knowledge has seemed to grow enormously in the last half century is the benthos. Many of the benthic examples used in The Oceans (1942) came from the Challenger Expedition (1873-75) and from the synthesis and subsequent publications by Murray regarding that

\section{The speculative}

nature of the text... is also a strength . . . 